\title{
CAÇADORES-RECOLECTORES NO VALE DO SADO, AMBIENTE, RECURSOS E TECNOLOGIA LÍTICA: O CASO DE ARAPOUCO (ALCÁCER DO SAL)
}

\author{
MARIANA DINIZ ${ }^{(1)} \&$ DIANA NUKUSHINA ${ }^{(2)}$
}

Resumo:

\begin{abstract}
No vale do Sado, Arapouco apresenta-se como um sítio-chave para discussão das modalidades de implantação e funcionamento do conjunto de concheiros do Mesolítico final, desta região. Perspectivas anteriores têm defendido o carácter especializado e temporário de Arapouco, no contexto deste complexo de concheiros, tratando-se do sítio mais a jusante até agora identificado e com maior abundância de restos de ictiofauna (ARNAUD 1989, 2000; GABRIEL 2010). A análise isotópica realizada sobre um esqueleto humano proveniente do concheiro de Arapouco demonstra a importância dos recursos marinhos, na dieta deste indivíduo (CuNHA \& UMBELINO 2001). Não obstante, a cultura material deste sítio não foi alvo de estudo sistemático até à data, apesar da sua reconhecida importância para o conhecimento do povoamento e da paleo-economia pré-históricas. Neste sentido, a análise da indústria lítica de Arapouco afigurou-se como uma tarefa imperativa, apresentandose aqui os primeiros resultados. Detectar na indústria lítica de Arapouco elementos específicos que conectem o sítio com a exploração especializada de recursos aquáticos constitui o objectivo central desta análise.
\end{abstract}

Palavras-chave: Mesolítico, Vale do Sado, Arapouco, Indústria lítica, Sítio logístico

Abstract:

\begin{abstract}
Hunter-gatherers in the Sado valley, environment, resources and lithic technology: the case of Arapouco (Alcácer do Sal)

In the Sado valley, Arapouco appears as a key-site to the discussion of the settlement and functional organization of the Late Mesolithic shell middens of this region. Previous perspectives have been stated a specialized and temporary character of Arapouco in this shell middens complex, being this site the most downstream, with the major quantity of icthiofaunal remains until now (ARNAUD 1989, 2000; GABRIEL 2010). The isotopic analyses on a human skeleton from Arapouco show the importance of the marine resources on the diet of this individual (CUNHA \& UMBELINO 2001). Nevertheless, the material culture of Arapouco was not object of a systematic study until now, in spite of the importance of this site to the knowledge of the prehistoric settlement and economy. Thus an analysis of the lithic industry from Arapouco appeared imperative, being presented in this paper the first results of this work. The main aim was to detect specific elements in the lithic industry of Arapouco which are connectable with a specialized exploitation of aquatic resources.
\end{abstract}

Keywords: Mesolithic, Sado valley, Arapouco, Lithic industry, Site function

Received: 24 July, 2014; Accepted: 20 November, 2014

\section{INTRODUÇ̃̃̃}

No vale do Sado, Arapouco (Alcácer do Sal, Setúbal) apresenta-se como um sítio-chave para a discussão das modalidades de implantação e funcionamento do conjunto de concheiros conhecidos nesta região (Fig. 1). O concheiro implanta-se sobre um pequeno cabeço, a $47 \mathrm{~m}$ de
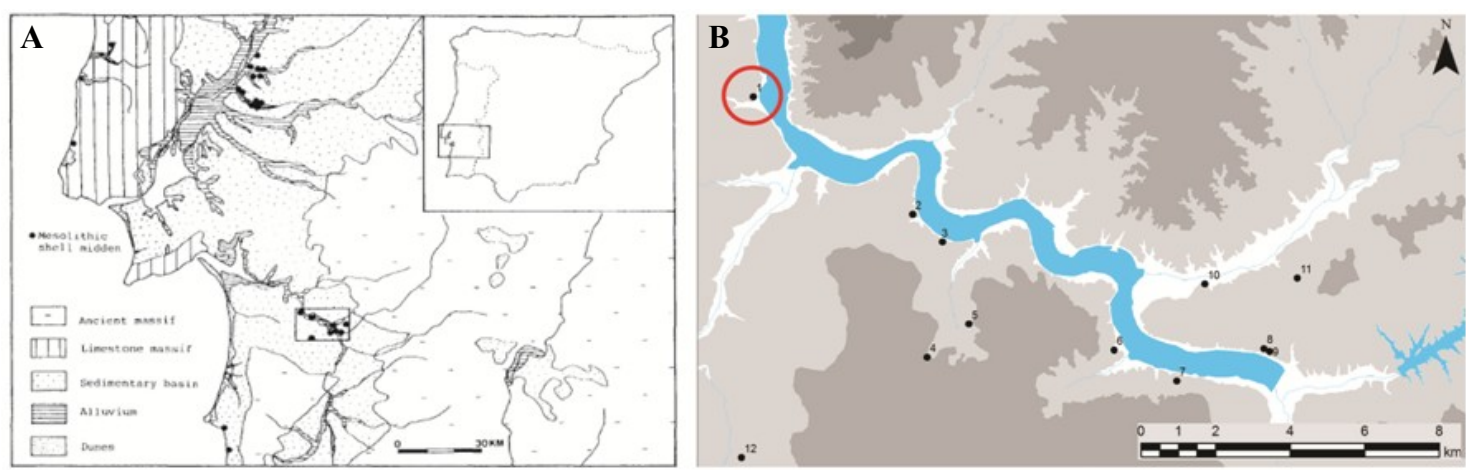

Fig. 1. Localização de Arapouco: A) na Península Ibérica (ARNAUD 1989), B) nos concheiros do vale do Sado (adaptado de DINIZ \& ARIAS, 2012, p. 141, fig. 1).

Fig. 1. Location of Arapouco: A) in the Iberian Peninsula (ARnAud 1989), B) in the shell middens complex of the Sado valley (adapted from DINIZ \& ARIAS 2012, p. 141, fig.1).

(1) Centro de Arqueologia da Universidade de Lisboa (UNIARQ), Faculdade de Letras da Universidade de Lisboa. E-mail: m.diniz@fl.ul.pt

${ }^{(2)}$ Mestre em Arqueologia, Faculdade de Letras da Universidade de Lisboa. E-mail: dnukushina@campus.ul.pt 
altitude, na margem esquerda do rio Sado, apresentando um excelente domínio visual sobre o rio (Figs. 2 e Fig. 3). As coordenadas UTM (WGS84) são 544338 (lat.) e 4240364 (long.).

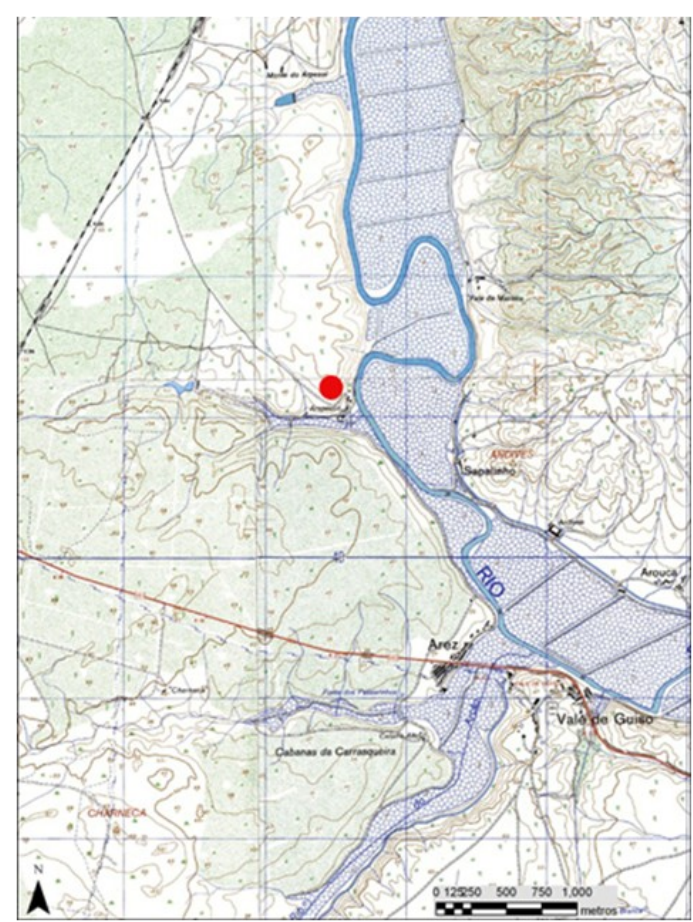

Fig. 2. Localização de Arapouco na Carta Militar de Portugal (2010), escala 1:25000, extratos das folhas n-477 e 486

Fig. 2. Location of Arapouco in the Military Map of Portugal 1:25000, extracts from the sheets $n-477$ e 486 .

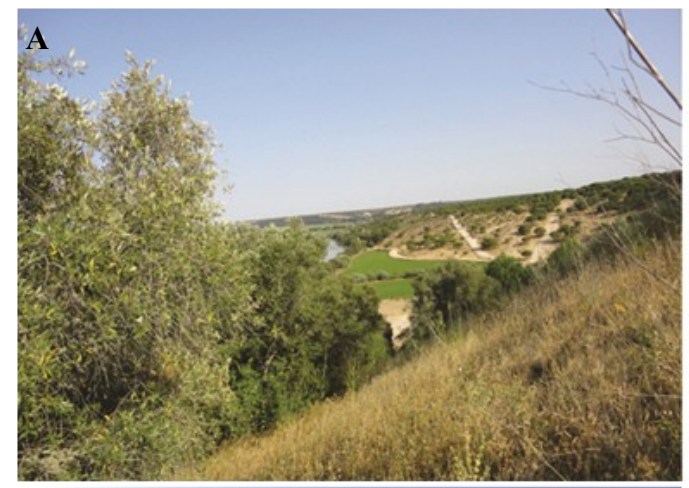

B

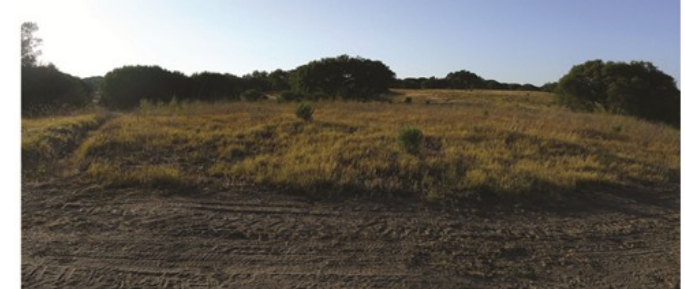

Fig. 3. Concheiro de Arapouco: A) vista para o rio Sado, B) área de dispersão do concheiro.

Fig. 3. Arapouco shell midden: A) view of the Sado river, B) general view.
O sítio foi escavado entre os anos 1950 e 1960 , pelos trabalhadores de Manuel Heleno, no quadro das campanhas que o então director do Museu Nacional de Arqueologia dirigia na região, seguindo a metodologia sistematicamente utilizada no Sado, que consistia na abertura de uma série de sondagens para delimitar o concheiro, e a abertura de uma área ampla, quase central, a partir da identificação dos enterramentos aí preservados (ARNAUD 2000).

Perspectivas anteriores têm defendido um carácter especializado e temporário de Arapouco dentro deste complexo de concheiros, tratando-se do sítio mais a jusante até agora identificado e com maior abundância de restos de ictiofauna, por contraponto à escassez de fauna terrestre, de acordo com as análises publicadas por J. Arnaud (1989, 2000), e ainda em curso por S. Gabriel (2010). Várias espécies de peixe têm vindo a ser identificadas, incluindo tubarão, robalo e dourada (GABRIEL, PRISTA \& COSTA 2012). Apesar do pequeno número de dados publicados, as análises isotópicas de esqueletos humanos provenientes do Sado (Tabela 1), apresentam-se como outro elemento a favor desta hipótese, sendo que da totalidade dos restos analisados, apenas o indivíduo, proveniente de Arapouco, apresenta uma dieta aquática significativa, com os recursos marinhos a atingirem $44 \%$ da sua alimentação. A leitura conjunta desta informação geográfica - relacionada com a implantação espacial do sítio; antropológica - relacionada com as dietas, e faunística - relacionada com os restos ictiológicos, parece conferir a Arapouco uma relação particular com o ambiente aquático, menos documentada em outros concheiros.

Neste sentido, e no âmbito da linha de revisão e estudo das colecções provenientes dos concheiros do Sado e depositadas no Museu Nacional de Arqueologia, do projecto SADO-MESO, procedeu-se à análise tecno-tipológica da indústria lítica de Arapouco. Importava detectar no conjunto artefactual reflexos de uma adaptação específica ao meio estuarino e a tarefas essencialmente relacionadas com os recursos aquáticos, identificando potenciais diferenças em relação a conjuntos artefactuais de outros concheiros do Sado já analisados (ARAÚJO 1995-1997; MARCHAND 2001; NUKUSHINA 2012).

\section{A INDÚSTRIA LÍTICA DE ARAPOUCO}

\subsection{Metodologia}

Em função da problemática colocada, foi efectuada a caracterização tecno-tipológica da indústria lítica de Arapouco, recolhida durante as intervenções de Manuel Heleno (anos de 1950-60). A abordagem seguiu os pressupostos teórico-metodológicos subjacentes ao conceito de "cadeia operatória" (TIXIER, INIZIAN \& ROCHE, 1980; INIZIAN et al. 1999), e foi realizada de acordo com os critérios tecno-tipológicos definidos para o estudo das indústrias de pedra lascada do Paleolítico Superior e do Mesolítico, no Ocidente peninsular (ZILHÃO 1997; ARAÚJO 1995-1997, 2011). 
Tabela 1. Dados isotópicos dos esqueletos humanos dos concheiros do Sado. Cálculo da dieta marinha de acordo com a expressão matemática utilizada por Ambrose (1993)

Table 1. Isotopic data from the human skeletons of the Sado shell middens. Marine diet \% calculated through the formula established by Ambrose (1993)

\begin{tabular}{|c|c|c|c|c|c|c|c|c|}
\hline Sítio & Contexto & Amostra & Lab. & $\delta^{13} \mathrm{C}(\%)$ & $\begin{array}{c}\text { Dieta } \\
\text { marinha } \\
(\%)\end{array}$ & $\underset{\text { BP }}{\text { Data }^{14} C}$ & $\begin{array}{c}\text { Data }{ }^{14} \mathrm{C} \\
\text { Cal BC (2 } \\
\sigma)^{*}\end{array}$ & $\begin{array}{c}\text { Referência } \\
\text { bibliográfica }\end{array}$ \\
\hline Arapouco & $\begin{array}{c}\text { Esqueleto } \\
2 \mathrm{~A}\end{array}$ & Homo & Sac-1560 & $-16,92$ & 44 & $7200 \pm 130$ & $6252-5679$ & $\begin{array}{c}\text { CUNHA \& } \\
\text { UMBELINO } 2001\end{array}$ \\
\hline Amoreiras & Esqueleto 5 & Homo & Beta- 125110 & $-20,8$ & & $7230 \pm 40$ & $6211-6021$ & $\begin{array}{c}\text { CUNHA \& } \\
\text { UMBELINO } 2001\end{array}$ \\
\hline \multirow{2}{*}{$\begin{array}{c}\text { Cabeço do } \\
\text { Pez }\end{array}$} & Esqueleto 4 & Homo & Beta-125109 & $-22,6$ & & $6760 \pm 40$ & & $\begin{array}{c}\text { CUNHA \& } \\
\text { UMBELINO } 2001\end{array}$ \\
\hline & Esqueleto 4 & Homo & Sac-1558 & $-19,28$ & & $6740 \pm 110$ & $5867-5479$ & $\begin{array}{c}\text { CUNHA \& } \\
\text { UMBELINO } 2001\end{array}$ \\
\hline
\end{tabular}

* Datas calibradas a partir de OxCal 4.2 (Bronk Ramsey 2009) utilizando a curva atmosférica IntCal 13 (Reimer et al. 2013) para amostras terrestres. As amostras Sac-1560 e Sac-1558 obtidas a partir de amostras humanas com dietas mistas (Richards \& Hedges 1999) foram calibradas segundo a curva Marine 13 (Reimer et al. 2013) e o $\Delta \mathrm{R}$ regional para o vale do Sado: $\Delta \mathrm{R}=-100 \pm 155$ (Martins et al. 2008; Soares comunicação pessoal).

\subsection{Características e contextualização do con- junto analisado}

Foram classificadas as 3841 peças líticas provenientes das intervenções de M. Heleno, neste concheiro (Tabela 2). Os materiais têm registo de proveniência de 12 secções, 5 sondas e diversos esqueletos, mas para uma parte considerável do material, cerca de $24,5 \%$ do conjunto, desconhece-se a exacta proveniência. O material lítico associado a esqueletos apenas 55 peças identificadas como provável espólio votivo - não tem qualquer característica técnica ou tipológica que o diferencie do restante. Em termos de camadas estratigráficas, apenas se faz menção a três camadas. A maior parte das peças provém da primeira e segunda camadas, respectivamente $39,8 \%$ e $31,7 \%$, registando-se uma quebra muito acentuada na $3^{\mathrm{a}}$ camada (entre os 50 e $75 \mathrm{~cm}$ ), onde se recuperou apenas $5 \%$ do conjunto lítico. $\mathrm{Na} 4^{\mathrm{a}}$ camada não foi recuperado qualquer material, e da $5^{\mathrm{a}}$ camada provém uma única peça. A presença maioritária de material lítico na $1^{\mathrm{a}}$ camada $(0-25 \mathrm{~cm})$ estará relacionada com fenómenos pós-deposicionais de migração vertical de elementos micro-laminares já registada em outras ocupações sobre sedimentos arenosos (e.g. DINIZ 2007, p. 76).

A partir da leitura da Tabela 2, é possível constatar que em Arapouco, os restos de talhe constituem a categoria tecnológica numericamente mais representativa $(57,12 \%)$, seguida pelo material de debitagem. Os utensílios retocados constituem uma fracção pequena, do conjunto. Os núcleos encontram-se particularmente mal representados, assim como o material de preparação e manutenção dos mesmos.

Tabela 2. Total de peças líticas talhadas analisadas do concheiro de Arapouco (MNA)

Table 2. Total of the lithic materials analyzed from the Arapouco shell midden (MNA)

\begin{tabular}{cccc}
\hline Categoria tecnológica & Sub-categoria & Total & $\mathbf{\%}$ \\
\hline Núcleos & & $\mathbf{9 7}$ & $2,53 \%$ \\
Material de preparação/ & & $\mathbf{4 5}$ & $1,17 \%$ \\
manutenção & Peças de crista & 13 & $0,34 \%$ \\
& Tablettes & 23 & $0,60 \%$ \\
Material de debitagem (bruto) & Flancos & 9 & $0,23 \%$ \\
& & $\mathbf{4 0 5 8}$ & $27,54 \%$ \\
Utensílios retocados & Lâminas & 11 & $0,29 \%$ \\
& Lamelas & 564 & $14,68 \%$ \\
Leça esquirolada & Lascas & 483 & $12,57 \%$ \\
Restos de talhe & Geométricos & $\mathbf{4 4 4}$ & $11,56 \%$ \\
& Lamelas retocadas & 106 & $2,76 \%$ \\
& Utensílios de fundo comum & 119 & $3,10 \%$ \\
& Diversos & 166 & $4,32 \%$ \\
& & 53 & $1,38 \%$ \\
& & $\mathbf{3}$ & $0,08 \%$ \\
& Fragmentos & $\mathbf{2 1 9 4}$ & $57,12 \%$ \\
& Esquírolas & 2059 & $53,61 \%$ \\
& Microburis & 75 & $1,95 \%$ \\
& & 60 & $1,56 \%$ \\
& & 3841 & $100,00 \%$ \\
\hline
\end{tabular}




\subsection{Aprovisionamento e características das matérias-primas}

Em Arapouco, verifica-se uma generalizada utilização de rochas siliciosas, nomeadamente chertes $(64,67 \%)$, de tonalidade acinzentada e acastanhada clara. O xisto silicioso está representado em menor quantidade $(22 \%)$. Por outro lado, para além do jaspe $(4,45 \%)$ e do quartzo hialino $(6,51 \%)$, outras matérias-primas encontram-se muito mal representadas, identificandose esta como uma indústria de reduzida variabilidade litológica (Fig. 4), ao nível de todas as categorias tecnológicas (Tabela 3). Em alguns casos, a observação das matérias-primas ficou condicionada pela frequente presença de concreções de concheiro. A presença de vestígios de córtex é bastante evidente no conjunto, $29 \%$ dos produtos debitados são corticais ou semicorticais, destacando-se a sua presença no escasso número de lâminas em bruto e núcleos, onde se apresenta sob a forma de córtex rolado.

Aparentemente, e segundo a investigação que tem vindo a ser recentemente realizada ao nível das matérias-primas, as rochas utilizadas seriam recolhidas nas proximidades, sobretudo em conglomerados paleogénicos (PIMENTEL et al. 2013).

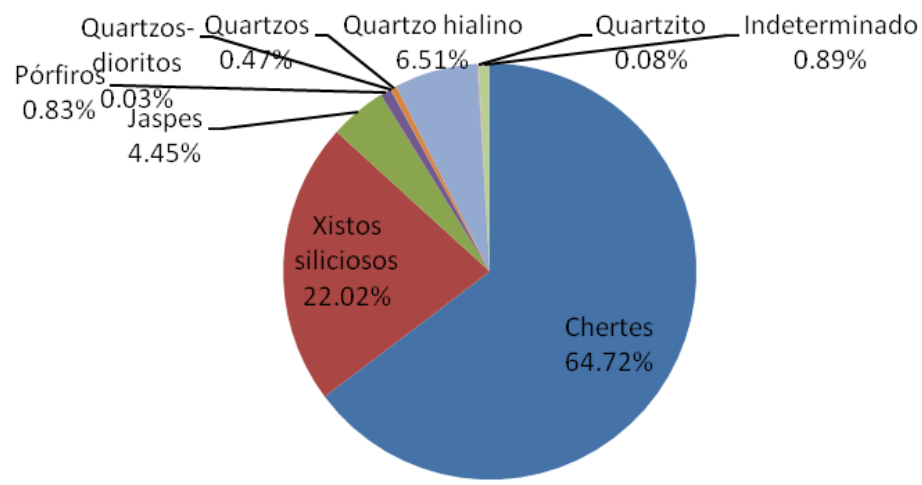

Fig. 4. Matérias-primas representadas no conjunto lítico de Arapouco (total). Fig. 4. Raw-materials of the lithic assemblage of Arapouco (total).

Tabela 3. Total de peças líticas por categoria tecnológica e matéria-prima do concheiro de Arapouco (MNA) Table 3. Total of the lithic materials from the Arapouco shell midden - technological categories and raw materials (MNA)

\begin{tabular}{|c|c|c|c|c|c|c|}
\hline \multirow[t]{2}{*}{ Categoria tecnológica } & \multicolumn{5}{|c|}{ Matéria -prima } & \multirow[t]{2}{*}{ Total } \\
\hline & Chert & Xisto Silicioso & Quartzo & Jaspe & Outras & \\
\hline Núcleos & 75 & 9 & 4 & 8 & 1 & 97 \\
\hline $\begin{array}{l}\text { Material de preparação/ } \\
\text { manutenção }\end{array}$ & 21 & 3 & 0 & 1 & 20 & 45 \\
\hline $\begin{array}{l}\text { Material de debitagem } \\
\text { (bruto) }\end{array}$ & 765 & 210 & 22 & 54 & 7 & 1058 \\
\hline Utensílios retocados & 323 & 77 & 5 & 25 & 17 & 447 \\
\hline Restos de talhe & 1295 & 546 & 238 & 83 & 32 & 2194 \\
\hline Total (inclui fragmentos) & 2479 & 845 & 269 & 171 & 77 & 3841 \\
\hline
\end{tabular}

\subsection{Análise tecno-tipológica}

\subsubsection{Núcleos}

Verifica-se uma elevada incidência de acidentes de talhe e defeitos nos núcleos $(67,16 \%)$, sobretudo ressaltos, o que demonstra a dificuldades no talhe destas matérias-primas. Embora em muitos casos tenha sido impossível determinar o suporte, a maioria dos núcleos inteiros utiliza, como volume inicial, seixos de pequena dimensão $(58,21 \%)$.
Em termos dos produtos debitados, os núcleos apontam para uma maior representatividade da debitagem de lascas, ao invés de lamelas. Há uma maior quantidade de núcleos com negativos exclusivamente de lascas $(19,40 \%)$, em relação aos núcleos que apenas apresentam extrações de lamelas $(10,45 \%)$. O mesmo se verifica ao nível dos núcleos que apresentam negativos de extrações de diferente morfometria (lascas, lamelas, esquírolas), dominando aqueles destinados à produção de las- 
cas e de outro suporte $(67,16 \%)$.

Os núcleos apresentam planos de talhe frequentemente lisos (46,21\%), embora a facetagem seja significativa, registada em $43 \%$ dos núcleos. As extracções apresentam mais frequentemente uma orientação múltipla (32,84\%), embora a orientação unidireccional $(22,39 \%)$ e ortogonal $(22,39 \%)$ tenham alguma importância. Os núcleos prismáticos são os mais frequentes (77,61\%) (Fig. 5), destacandose, em menor grau, os núcleos informes/poliédricos (8,96\%). A presença de blocos debitados e choppers/ chopping-tools tem algum significado (10,45\%),

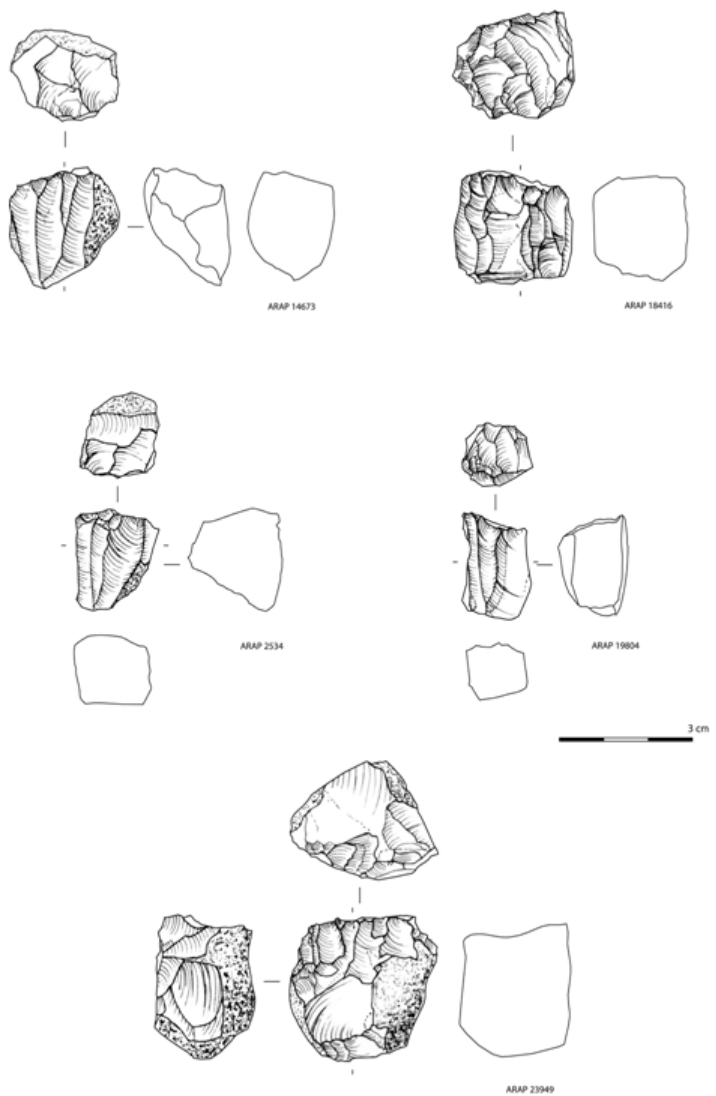

Fig. 5. Arapouco, núcleos prismáticos (MNA).

Fig. 5. Arapouco, prismatic cores (MNA).

tendo estes, com maior frequência, um carácter macrolítico, utilizando preferencialmente rochas não-siliciosas. A maior parte dos núcleos foi utilizada intensivamente $(50,75 \%)$, encontrando-se alguns em estado de esgotamento (32,84\%), sobretudo no caso dos núcleos em rochas siliciosas. Parte considerável terá sido abandonada devido aos defeitos das matérias-primas $(41,79 \%)$. Os padrões métricos dos núcleos inteiros expressam, em geral, o seu reduzido tamanho, nomeadamente os comprimentos, com uma média inferior a $30 \mathrm{~mm}$ (Tabela 4).

Quanto ao material de preparação e manutenção do núcleo, este não ultrapassa os $2 \%$ do total de peças, em conformidade com a escassa representatividade desta categoria nos outros sítios do Sado já analisados (ARAÚJO 1995-1997; MAR-
CHAND 2001; NUKUSHINA 2012). Deste conjunto, destacam-se as tablettes $(51,11 \%)$, e em segundo lugar, as peças de crista $(28,89 \%)$.

Tabela 4. Padrões métricos dos núcleos inteiros Table 4. Metrical patterns of the complete cores

\begin{tabular}{cc}
\hline Padrões métricos & Total \\
\hline Peso (g) & 54,20 \\
Média & 121,89 \\
Desvio-padrão & \\
Comprimento (mm) & 29,96 \\
Média & 17,83 \\
Desvio-padrão & \\
Largura (mm) & 29,65 \\
Média & 17,05 \\
Desvio-padrão & \\
Espessura (mm) & 23,50 \\
Média & 12,82 \\
Desvio-padrão & \\
Comprimento do eixo & \\
maior de debitagem (mm) & 17,92 \\
Média & 7,73 \\
Desvio-padrão & 67,00 \\
N &
\end{tabular}

\subsubsection{Produtos de debitagem}

O material de debitagem constitui o segundo grupo mais representativo da colecção $(27,54 \%)$. Neste caso, a representatividade de lamelas e lascas é similar (Tabela 5). Quando considerada a totalidade das peças, a percentagem de lamelas $(53,31 \%)$ é ligeiramente superior à de lascas $(45,65 \%)$, mas quando nos cingimos ao NMI, ou seja, contabilizando apenas as peças inteiras e os fragmentos proximais, as lascas apresentam-se numericamente superiores $(56,86 \%)$, face às lamelas $(41,90 \%)$.

Tabela 5. Total dos produtos de debitagem em Arapouco Table 5. Blank types from Arapouco (by Total and MNI).

\begin{tabular}{lllll}
\hline & Total & \multicolumn{3}{c}{ NMI } \\
\hline Lascas & $45,65 \%$ & 483 & $56,86 \%$ & 460 \\
Lâminas & $1,04 \%$ & 11 & $1,24 \%$ & 10 \\
Lamelas & $53,31 \%$ & 564 & $41,90 \%$ & 339 \\
Total & $100,00 \%$ & 1058 & $100,00 \%$ & 809 \\
\hline
\end{tabular}

À semelhança de outras categorias tecnológicas, a utilização de rochas não-siliciosas em lascas é escassa $(4,93 \%)$, sendo visível uma preferência pelos chertes $(63,17 \%)$ e xistos siliciosos $(28,40 \%)$. A maior parte das lascas não apresenta vestígios de córtex $(66,05 \%)$, destacando-se, no entanto, algumas peças semi-corticais $(21,53 \%)$. Os talões são maioritariamente lisos, os bolbos e as 
secções são variáveis. Os bordos tendem a ser irregulares, convergentes ou divergentes. Quando foi possível identificar os negativos de extracção, apenas em 196 produtos, a maior parte destes apresentava negativos concordantes em relação ao eixo de debitagem $(85,71 \%)$. Os perfis tendem a ser direitos $(88,93 \%)$ e as ondas de talhe são frequentemente invisíveis $(83,23 \%)$. Os acidentes de talhe não são frequentes, destacando-se alguns casos de duplo bolbo $(2,07 \%)$.

As dimensões das lascas inteiras apontam para o talhe de suportes de pequena dimensão e relativamente estandardizado. A larga maioria das lascas tem dimensões inferiores a $40 \mathrm{~mm}$ de comprimento e $30 \mathrm{~mm}$ de largura (Figs. 6 e 7, Tabela 6).

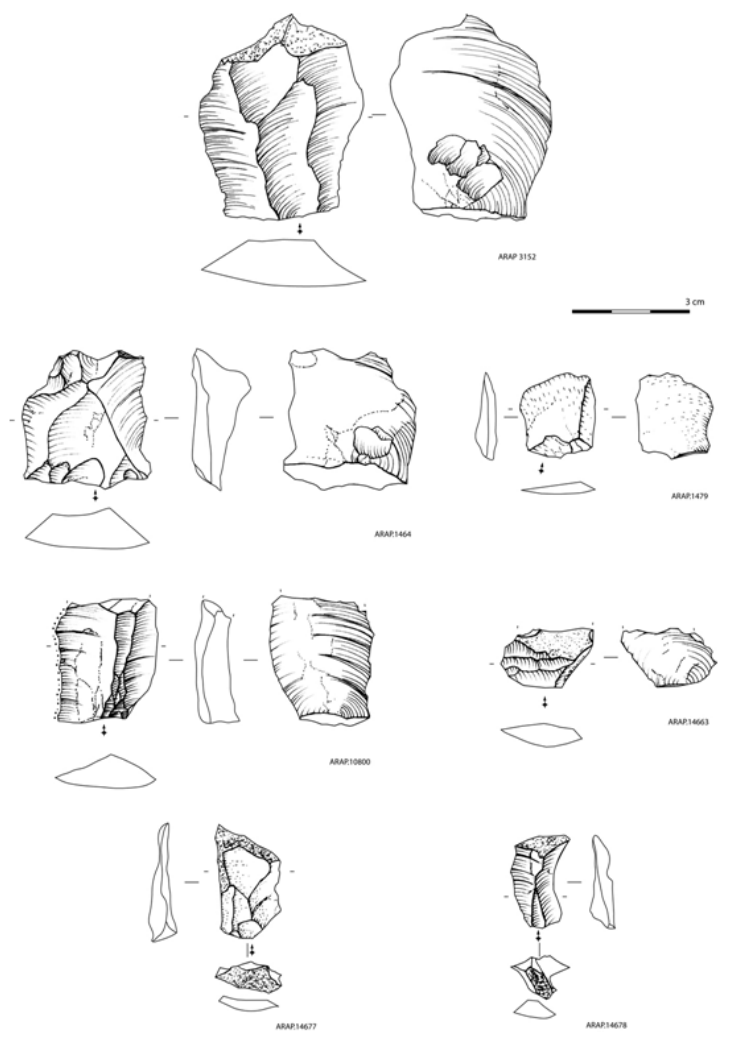

Fig. 6. Arapouco, lascas em bruto (MNA).

Fig. 6. Arapouco, unretouched flakes.

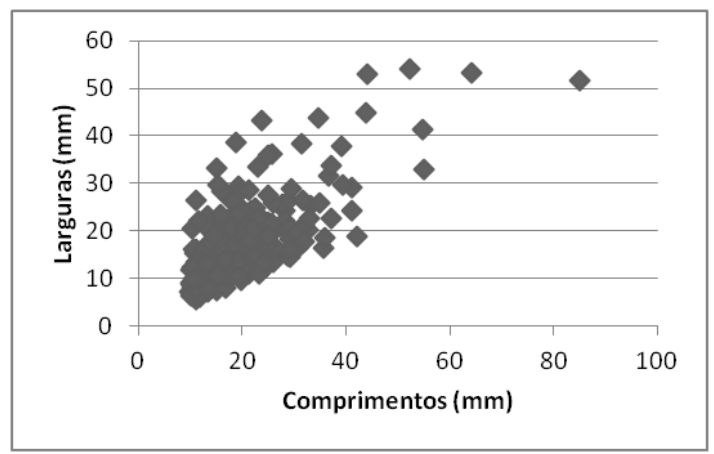

Fig. 7. Correlação dos comprimentos e larguras das lascas inteiras (mm). Fig. 7. Lengths and widths correlation of the complete flakes (mm).
Tabela 6. Padrões métricos das lascas brutas inteiras Table 6. Metrical patterns of the unretouched and complete flakes

\begin{tabular}{cc}
\hline Padrões métricos & Total \\
\hline Comprimento & 20,00 \\
Média & 9,20 \\
Desvio-padrão & \\
Largura & 17,18 \\
Média & 8,43 \\
Desvio-padrão & \\
Espessura & 5,12 \\
Média & 3,22 \\
Desvio-padrão & 280,00 \\
$\mathbf{N}$ &
\end{tabular}

\subsubsection{Lâminas}

As lâminas são residuais (11 peças), sendo claro que não constituíam o principal objectivo do talhe. Os vestígios de córtex estão presentes na maioria das peças $(63,64 \%)$, sendo estas semicorticais. Os talões revelam, também, a escassa preparação na produção destes suportes, sendo maioritariamente lisos $(36,36 \%)$ e corticais $(27,27 \%)$. As secções também não apresentam nenhuma tendência, o mesmo se verificando para os bordos, que apresentam diversidade e irregularidade. Os perfis tendem a ser direitos. As ondas de talhe são invisíveis.

Os valores métricos mostram a reduzida dimensão das lâminas, nomeadamente ao nível dos comprimentos. No que toca às larguras, é evidente a proximidade em relação ao limite máximo habitualmente utilizado para as lamelas $(12 \mathrm{~mm})$ (Tabela 7).

Tabela 7. Padrões métricos das lâminas inteiras Table 7. Metrical patterns of the complete blades

\begin{tabular}{cc}
\hline Padrões métricos & Total \\
\hline Comprimento & 34,25 \\
Média & 4,96 \\
Desvio-padrão & \\
Largura & 15,67 \\
Média & 2,27 \\
Desvio-padrão & \\
Espessura & 6,20 \\
Média & 2,43 \\
Desvio-padrão & 6,00 \\
N & \\
\hline
\end{tabular}




\subsubsection{Lamelas}

Embora não constituam o conjunto mais abundante, as lamelas são parte significativa dos produtos debitados $(41,90 \%$ do NMI) (Fig. 8). Totalizam as 564 peças, encontrando-se apenas $9,57 \%$ em estado inteiro. A maior parte não apresenta vestígios de córtex $(82,98 \%)$, tendo, no entanto, as peças semi-corticais alguma representatividade $(11,70 \%)$.

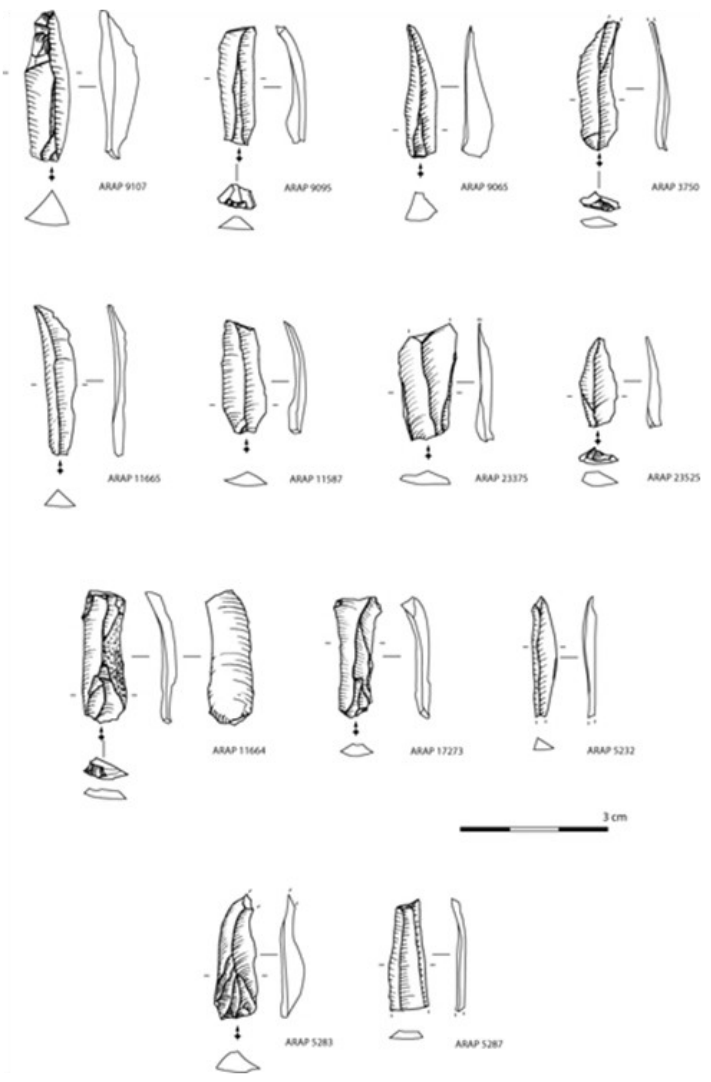

Fig. 8. Arapouco, lamelas em bruto (MNA).

Fig. 8. Arapouco, unretouched bladelets (MNA).

Os talões são maioritariamente lisos $(37,46 \%)$, diedros $(28,32 \%)$ ou facetados $(24,78 \%)$. $\mathrm{O}$ estrangulamento dos bordos junto ao talão é raro $(2,36 \%)$. Os bolbos surgem pronunciados, quer difusos, com alguma frequência de esquirolamento $(38,35 \%)$. As secções não apresentam uma tendência particular. Nas peças inteiras, os bordos tendem a ser paralelos $(35,19 \%)$ ou convergentes $(29,63 \%)$ e os negativos dorsais, quando visíveis, concordantes em relação ao eixo da debitagem, maioritariamente paralelos. Os perfis tendem a ser direitos $(50 \%)$. As ondas de percussão são invisíveis na maioria $(85,11 \%)$. Os acidentes de talhe são pouco frequentes. Embora a maioria das peças se encontre fracturada, a identificação do processo de fracturação foi impossível na maioria dos casos.

No que toca às dimensões, verifica-se uma forte estandardização, quer ao nível dos compri- mentos, quer das espessuras (Tabela 8). Observando por classes de $5 \mathrm{~mm}$, verifica-se a maior frequência dos comprimentos na classe 19-24 mm, seguida pela classe 14-19 $\mathrm{mm}$. De destacar, na debitagem de lamelas, a procura de produtos com larguras compreendidas entre os 5 e os $8 \mathrm{~mm}$, com um pico a registar-se nos 6-7 mm (Fig. 9), numa tendência própria das indústrias micro-laminares.

Tabela 8. Padrões métricos das lamelas inteiras Table 8. Metrical patterns of the complete bladelets

\begin{tabular}{cc}
\hline Padrões métricos & Total \\
\hline Comprimento & \\
Média & 19,88 \\
Desvio-padrão & 5,45 \\
Largura & \\
Média & 7,70 \\
Desvio-padrão & 1,58 \\
Espessura & \\
Média & 2,87 \\
Desvio-padrão & 1,05 \\
Índice de alongamento & \\
(inteiras) & \\
Média & 2,60 \\
Desvio-padrão & 0,60 \\
$\mathbf{N}$ & 54 \\
\hline
\end{tabular}

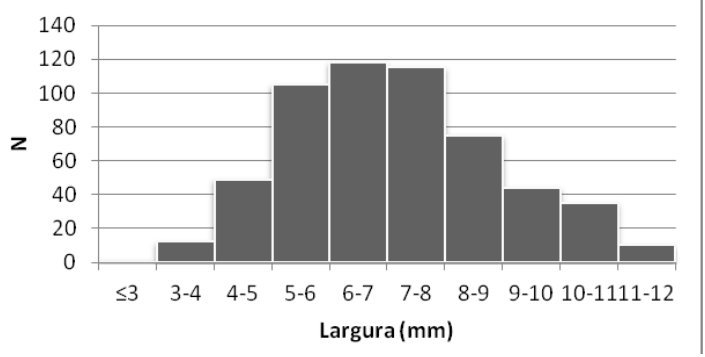

Figura 9. Larguras das lamelas brutas (total), por classes de $1 \mathrm{~mm}$.

Figure 9. Widths of unretouched bladelets (total) by $1 \mathrm{~mm}$ classes.

\subsubsection{Utensilagem}

Os utensílios retocados constituem apenas 11,56\% do total de peças analisado. Ao contrário de outros concheiros do Sado, os geométricos não constituem os utensílios dominantes, verificando-se uma maior quantidade de utensílios de fundo comum (37,39\%), seguidos pelas lamelas retocadas $(26,80 \%)$, e só depois os geométricos $(23,87 \%)$ (Fig. 10). Numa perspectiva global, verifica-se que o talhe de lascas e lamelas constituiria o objectivo central, para utilização em bruto ou posterior transformação através de retoque. Apesar de a utensilagem de fundo comum ser a mais frequente entre os utensílios, a utilização de lamelas como suporte da utensilagem é mais representativa $(54,05 \%)$. 


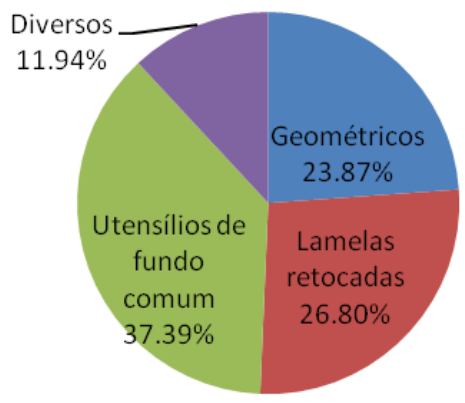

Fig. 10. Principais categorias de utensílios retocados presentes em Arapouco. Fig. 10. Main categories of the retouched tools in Arapouco.

\subsubsection{Utensílios de fundo comum}

Neste conjunto foram englobadas as lascas e lâminas retocadas, raspadores, raspadeiras, buris, entalhes, denticulados, furadores, truncaturas e utensílios compósitos sobre suporte não-lamelar, isto é, lasca, lâmina, fragmento ou seixo (Fig. 11). Constitui o conjunto de utensílios retocados mais numeroso $(37,39 \%)$, sobretudo devido ao peso das lascas retocadas $(63,86 \%)$, em que foram englobadas lascas com retoques atípicos, marginais, entalhes e denticulados (Tabela 9).

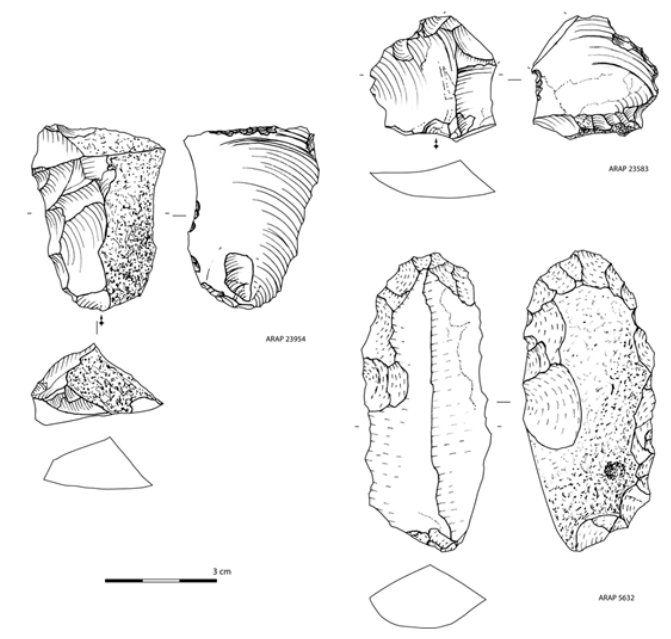

Fig. 11. Arapouco, utensílios de "fundo comum" (MNA). Fig. 11. Arapouco, 'common fond' tools (MNA).

Tabela 9. Utensilagem de fundo comum em Arapouco Table 9. Substrate tools tools in Arapouco

\begin{tabular}{ccc}
\hline Utensilagem & \multicolumn{3}{c}{ Total } \\
\hline Lasca retocada & $68,67 \%$ & 114 \\
Lâmina retocada & $3,61 \%$ & 6 \\
Raspador & $5,42 \%$ & 9 \\
Raspadeiras & $7,83 \%$ & 13 \\
Buril & $2,41 \%$ & 4 \\
Entalhe & $3,01 \%$ & 5 \\
Denticulado & $3,61 \%$ & 6 \\
Furador & $2,41 \%$ & 4 \\
Truncatura & $0,60 \%$ & 1 \\
Sobre seixo & $0,60 \%$ & 1 \\
Compósito & $1,81 \%$ & 3 \\
Total & $\mathbf{1 0 0 \%}$ & $\mathbf{1 6 6}$ \\
\hline
\end{tabular}

Em termos métricos, as lascas retocadas inteiras apresentam um comprimento médio ligeiramente superior $(26,45 \pm 10,91 \mathrm{~mm})$, ao das lascas brutas e que poderá ser explicado pela selecção de suportes de maior dimensão para retoque.

As raspadeiras constituem o segundo subgrupo mais numeroso deste conjunto $(7,83 \%)$, obtidas maioritariamente sobre seixo, mas também sobre lasca.

A utilização de suportes de tipo seixo ou fragmento atípico tem alguma importância neste conjunto $(15,66 \%)$, demonstrando o seu aproveitamento para a produção de utensilagem espessa.

\subsubsection{Lamelas retocadas}

No universo das lamelas retocadas $(26,80 \%$ dos utensílios), foram contabilizadas lamelas com retoque marginal, entalhes, denticulados, retoques atípicos, truncaturas, furadores, buris e lamelas de dorso abatido (Fig. 12). A maioria não apresenta vestígios de córtex $(86,55 \%)$. Os retoques são sempre curtos e maioritariamente directos e abruptos ou semi-abruptos. As lamelas com retoque marginal constituem o tipo mais frequente $(57,98 \%)$, seguidas pelas truncaturas $(14,29 \%)$ e entalhes $(13,45 \%)$ (Tabela 10).

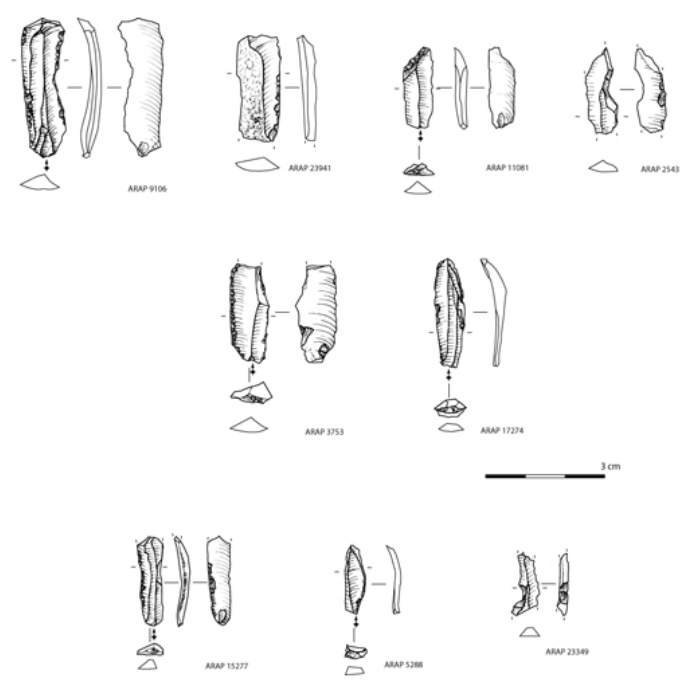

Fig. 12. Arapouco, lamelas retocadas (MNA).

Fig. 12. Arapouco, retouched bladelets (MNA).

Tabela 10. Classificação tipológica das lamelas retocadas Table 10. Typological classification of the retouched bladelets

\begin{tabular}{ccc}
\hline Lamelas retocadas & \multicolumn{2}{c}{ Total } \\
\hline Retoque marginal & $57,98 \%$ & 69 \\
Furador & $0,84 \%$ & 1 \\
Entalhe & $13,45 \%$ & 16 \\
Entalhe+retoque margi- & $3,36 \%$ & 4 \\
nal & & \\
Lamela de dorso & $2,52 \%$ & 3 \\
Buril & $1,68 \%$ & 2 \\
Retoque avulso/atípico & $5,88 \%$ & 7 \\
Truncatura & $14,29 \%$ & 17 \\
Total & $100 \%$ & 119 \\
\hline
\end{tabular}


Quando presentes, os talões apresentam-se maioritariamente diedros $(32,84 \%)$, lisos $(29,85 \%)$, ou facetados $(29,85 \%)$. Os bolbos são sobretudo pronunciados $(62,69 \%)$, com alguma presença de esquirolamento $(38,81 \%)$. Os bordos tendem a ser paralelos, sendo o estrangulamento junto ao talão praticamente ausente. Os perfis são mais frequentemente direitos $(50 \%)$. As ondas de percussão são maioritariamente invisíveis $(86,55 \%)$, e os acidentes de talhe pouco frequentes ( 8 casos).

Verifica-se que os valores métricos apresentados pelas lamelas retocadas se podem enquadrar dentro dos parâmetros verificados para as lamelas brutas e geométricos, nomeadamente ao nível das espessuras.

\subsubsection{Geométricos}

Os micrólitos geométricos detêm uma representatividade importante, embora não de forma dominante $(23,87 \%$ do total de utensílios). Os trapézios constituem o tipo mais frequente entre os geométricos $(78,30 \%)$, surgindo quer formas simétricas, quer assimétricas. De forma menos significativa, surgem alguns triângulos $(10,38 \%)$, sobretudo escalenos. Os segmentos constituem o tipo menos frequente $(6,60 \%)$, e as formas de transição são raras $(2,83 \%)$ (Tabela 11). Verifica-se uma tendência geral de diminuição do número de geométricos da primeira para a terceira camada do sítio, o que estará relacionado com processos tafonómicos de migração de material lítico, ao longo da sequência estratigráfica.

Tabela 11. Tipologia e sub-tipologias dos geométricos em Arapouco

Table 11. Typologies and sub-typologies of the geometrics of Arapouco

\begin{tabular}{llcc}
\hline $\begin{array}{l}\text { Tipologia de } \\
\text { geométricos }\end{array}$ & Sub-tipo & Total & \% \\
\hline Trapézio & & $\mathbf{8 3}$ & $\mathbf{7 8 , 3 0 \%}$ \\
& Simétrico & 30 & $28,30 \%$ \\
& Assimétrico & 24 & $22,64 \%$ \\
Triângulo & Indeterminado & 29 & $27,36 \%$ \\
& Isósceles & $\mathbf{1 1}$ & $\mathbf{1 0 , 3 8 \%}$ \\
& Escaleno & 7 & $1,89 \%$ \\
& & 2 & $6,60 \%$ \\
Segmento & Indeterminado & 2 & $1,89 \%$ \\
& Assimétrico & 1 & $\mathbf{6 , 6 0 \%}$ \\
& Simétrico & 5 & $0,94 \%$ \\
& & & $4,72 \%$ \\
Total & Indeterminado & 1 & $0,94 \%$ \\
& & $\mathbf{5}$ & $\mathbf{4 , 7 2 \%}$ \\
& Forma de & & \\
& transição & 3 & $2,83 \%$ \\
& & & $1,89 \%$ \\
& Indeterminado & 2 & $\mathbf{1 0 0 , 0 0 \%}$ \\
\hline
\end{tabular}

Os geométricos são obtidos quase integralmente sobre rochas siliciosas $(99,05 \%)$, a partir de lamelas, e formados maioritariamente por retoque abrupto e directo, apresentando forte uniformidade. Os vestígios de córtex são praticamente inexistentes. Os trapézios, cujas larguras originais se encontram conservadas, apresentam secções maioritariamente trapezoidais $(63,86 \%)$. O índice de fracturação é sempre inferior a $50 \%$, o que nos permite falar de um relativo bom estado de conservação das peças (Fig. 13).

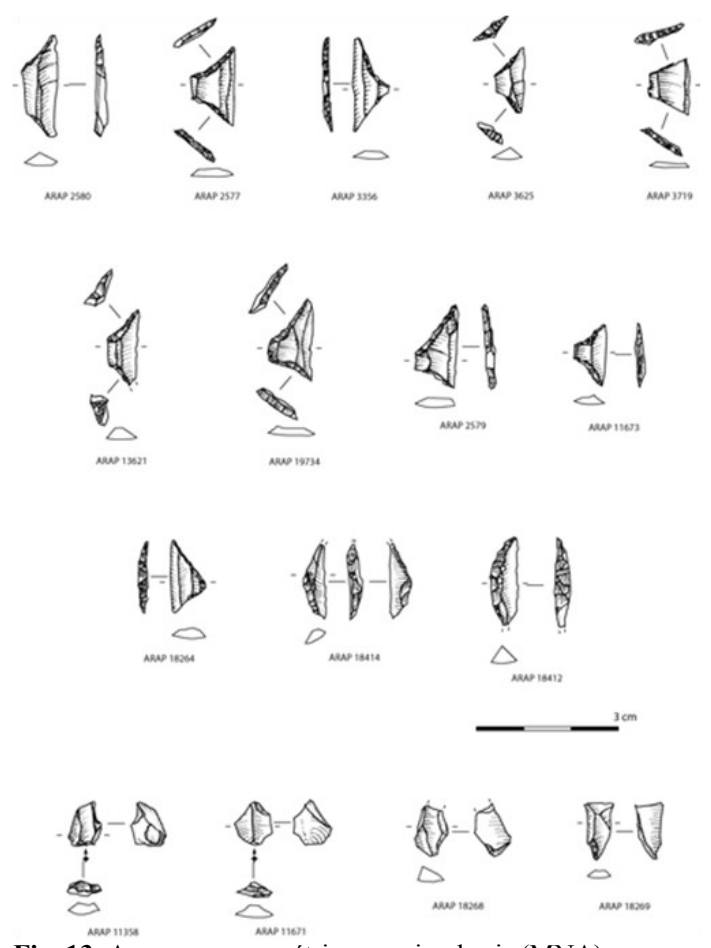

Fig. 13. Arapouco, geométricos e microburis (MNA).

Fig. 13. Arapouco, geometrics and microburins (MNA).

Ao nível das dimensões, verifica-se uma forte estandardização, em particular ao nível dos comprimentos e das espessuras, sendo a variação do alongamento médio, também, reduzida. Verifica-se que a maior frequência dos comprimentos surge na classe 14-16 mm, seguida pela classe $16-18 \mathrm{~mm}$ (Tabela 12).

Tabela 12. Padrões métricos dos geométricos

Table12. Metrical patterns of the geometrics

\begin{tabular}{cc}
\hline Padrões métricos & Total \\
\hline Comprimento (inteiros) & 15,39 \\
Média & 2,83 \\
Desvio-padrão & \\
Largura conservada (exclui \\
trapézios) \\
Média & 7,22 \\
Desvio-padrão & 1,61 \\
Largura original (trapézios) & \\
Média & 7,24 \\
Desvio-padrão & 1,27 \\
Espessura & \\
Média & 1,92 \\
Desvio-padrão & 0,44 \\
Índice de alongamento & \\
(inteiros) & \\
Média & 2,2 \\
Desvio-padrão & 0,58 \\
\hline
\end{tabular}


Isolando os trapézios inteiros, verifica-se, no que toca aos comprimentos e larguras, a ausência de agrupamentos distintos. As lamelas produzidas em Arapouco terão constituído os suportes dos geométricos, sendo os valores das larguras próximos (Fig. 14).

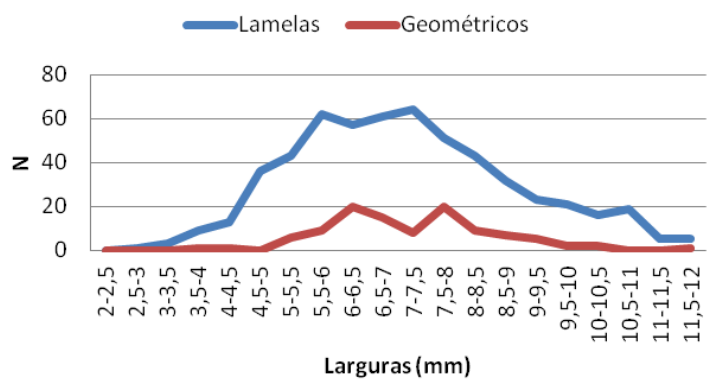

Fig. 14. Larguras comparadas das lamelas e geométricos (total), em Arapouco, por classes de 0,5 mm.

Fig. 4. Compared widths of bladelets and geometrics (total) in Arapouco, by $0,5 \mathrm{~mm}$ classes.

A técnica de fracturação por microburil encontra-se atestada pela presença dos característicos resíduos, obtidos quase inteiramente em rochas siliciosas (Fig. 13). Considerados apenas os geométricos inteiros, obtemos um rácio geométricosmicroburis de 1:1. A paridade entre estes valores, torna Arapouco no concheiro do Sado com a maior correspondência entre o número de geométricos e microburis. A relativa abundância destes resíduos poderá estar relacionada com o maior número de trapézios neste sítio e a necessidade de uma melhor definição das truncaturas características deste tipo morfológico. As larguras destes resíduos (média de $6,91 \pm 1,6 \mathrm{~mm}$ ), mostram a sua proximidade com as lamelas e geométricos. As espessuras dos microburis (média de 2,17 $\pm 0,56 \mathrm{~mm}$ ), aproximam-se dos valores obtidos para as lamelas.

\section{ESTRATÉGIAS DE EXPLORAÇÃO DA PEDRA EM ARAPOUCO - PRIMEIRAS CONCLUSÕES E INÍCIO DA DISCUSSÃO}

No conjunto lítico de Arapouco estão documentados todos os produtos tecnológicos resultantes das sucessivas etapas da cadeia operatória, apontando para a prática de talhe local, à semelhança de outros conjuntos já analisados, no vale do Sado (Poças de S. Bento, Cabeço do Rebolador, Várzea da Mó e Amoreiras).

Não se detectam, porém, cadeias operatórias diferenciadas segundo o tipo de matéria-prima, ao contrário, por exemplo, da situação verificada em Poças de S. Bento (ARAúJO 1995-1997), sendo dominante o uso de rochas siliciosas para todas as categorias tecnológicas. Não deixa de ser incongruente verificar que a produção lítica de Arapouco, em que há uma maior importância de lascas e utensílios de "fundo comum", apresente, por outro lado, uma utilização de rochas siliciosas intensiva e escasso uso de quartzos, rochas ígneas e metamórficas. No entanto, esta estratégia de utilização das matérias-primas pode, no caso do Sado, reflectir o aproveitamento intensivo dos recursos líticos localmente disponíveis, mais do que uma procura de adequação das qualidades das matérias-primas aos produtos finais. Assim, as diferenças detectadas no uso de matérias-primas patente em Arapouco deve reflectir a geologia local, mais do que outras selecções, aspecto a confirmar no terreno por levantamento geológico de pormenor. Ao nível tecno-tipológico, a principal particularidade deste sítio parece residir na importância do talhe de lascas, que ultrapassa o talhe lamelar, e que se encontra documentado pela abundância de núcleos com negativos de lascas, pelas lascas em bruto e, em simultâneo, pela utilização deste produto enquanto suporte da utensilagem. Com efeito, neste concheiro, o peso dos geométricos que constitui, nos outros contextos mesolíticos do vale do Sado, o grupo tipológico dominante (ARAÚJO 1995-97, p. 148; MARCHAND 2001, p. 107; NUKUSHINA 2012, p. 78), é aqui relativamente reduzido, possuindo a utensilagem de "fundo comum" a maior representatividade entre a utensilagem retocada. Em relação a outros sítios do Sado para os quais dispomos de dados, Arapouco destaca-se efectivamente pela presença de uma grande quantidade de lascas, por comparação com Amoreiras (NUKUSHINA 2012), apresentando-se mesmo como o sítio com maior quantidade de núcleos exclusivamente com negativos de lascas (Tabelas 13 e 14). O Cabeço do Rebolador, o segundo sítio mais a jusante neste troço do rio (Figura 1, n. ${ }^{\circ}$ ), possui também uma quantidade de lascas superior às lamelas (MARCHAND 2001, p. 103). Este é, também, o segundo sítio com maior quantidade de crustáceos (ARNAUD 1989, p. 623, fig. 7), e identicamente para o Cabeço do Rebolador é proposta uma conexão efectiva com a exploração dos recursos aquáticos (ARNAUD 1986). Nos restantes concheiros do Sado, até agora analisados, a debitagem lamelar é sempre preponderante.

Tabela 13. Representatividade dos núcleos para lascas (exclui núcleos mistos) no total de núcleos (inteiros e fragmentos) Table 13. Representation of the cores for flakes (excluding mixed cores) in the total of cores (complete and fragments)

\begin{tabular}{lll}
\hline Sítio & \% núcleos lascas & Bibliografia \\
\hline S. Bento & 13,7 & $\begin{array}{l}\text { ARAÚJO, 1995- } \\
1997\end{array}$ \\
Amoreiras & 12,1 & NUKUSHINA, 2012 \\
Arapouco & 18,56 & \\
\hline
\end{tabular}

Tabela 14. Representatividade das lascas no total dos conjuntos líticos analisados

Table 14. Representation of the flakes in the total of the lithic assemblages

\begin{tabular}{ccc}
\hline Sítio & \% lascas & Bibliografia \\
\hline S. Bento & 18,4 & ARAÚJO 1995- \\
Amoreiras & 7,63 & NUKUSHINA 2012 \\
Arapouco & 12,57 & \\
\hline
\end{tabular}


A destacar ainda, ao nível dos micrólitos geométricos, onde domina o trapézio, o peso escasso das armaduras em Arapouco, no campo da utensilagem, em contraste com o detectado em outros concheiros.

Apesar das particularidades deste sítio ao nível da produção lítica, é difícil associar esta diferença à tese de especialização funcional de Arapouco e, em concreto, a práticas piscatórias. A produção de suportes alargados, mas de pequena dimensão, parece ocorrer em consonância com a produção lamelar. Por outro lado, os utensílios de "fundo comum", com excepção das lascas retocadas, apresentam alguma diversidade tipológica, o que não reforça a possibilidade de especialização funcional do sítio. A realização de análises traceológicas poderá constituir uma via para a compreensão da funcionalidade destes elementos e associá-los ao processamento de peixe, ou de outros recursos aquáticos. No entanto, são ainda pouco frequentes as análises traceológicas associadas especificamente ao processamento de pescado, devido a dificuldades na identificação deste tipo de traços de uso, no material lítico (García Díaz \& Clemente Conte 2011). Contudo, a observação de traços de utilização conectados com os recursos aquáticos tem vindo a produzir resultados quer para contextos antigos associados a Neandertais (HARDY \& MONCEL 2011), quer na Península Ibérica, a sítios neolíticos como na Esparragosa, Andaluzia, onde foram detectados traços de uso em lâminas, relacionados com actividades de descamação, limpeza e corte de peixe (GIBAJA et al. 2010), o que demonstra ser esta uma via a explorar.

Embora vários elementos de carácter ambiental apontem para um carácter mais estuarino e aquático da ocupação em Arapouco, as particularidades tecno-tipológicas da indústria lítica devem ser interpretadas com alguma prudência, uma vez que não estão definidos quais os pacotes artefactuais especificamente correlacionáveis com uma economia marítima, e que papel poderiam desempenhar, neste quadro, lascas e utensílios de fundo comum, instrumentos, por definição, multifuncionais.

\section{AGRADECIMENTOS}

Ao Museu Nacional de Arqueologia, que disponibilizou para estudo a colecção de Arapouco, à Fundação para a Ciência e Tecnologia, através do financiamento do projecto 'Retorno ao Sado: um caso entre os últimos caçadores-recolectores e a emergência das sociedades agro-pastoris no Sul de Portugal' (PTDC/HIS-ARQ/121592/2010), no âmbito do qual foi produzido este artigo. A Rita Stjerna pela calibração das datas apresentadas.

\section{REFERÊNCIAS}

AMBROSE, S.H. 1993. Isotopic analysis of paleodiets: methodological and interpretive considerations. In: $\mathrm{M}$ K. Sandford (ed.), Investigations of Ancient Human Tissue. Chemical Analyses in Anthropology, University of North Carolina at Greensboro: Gordon and Breach Science Publishers: 59-130.
ARAúJO, A. C. 1995/1997. A indústria lítica do concheiro de Poças de S. Bento (Vale do Sado) no seu contexto regional. O Arqueólogo Português, S4, 13-15: 87-159.

ARAúJo, A. C. 2011. O concheiro de Toledo no contexto do Mesolítico Inicial do litoral da Estremadura. Lisboa: Instituto Português de Arqueologia, Trabalhos de Arqueologia 51

Arnaud, J. M. 1989. The Mesolithic Communities of the Sado Valley, Portugal, in their Ecological Setting. In DONSALL, C. (ed.) - The Mesolithic in Europe. III International Symposium. Edimburgo: John Donald: 614-632.

ARnAUD, J. M. 2000. Os concheiros mesolíticos do vale do Sado e a exploração dos recursos estuarinos (nos tempos pré-históricos e na actualidade). In Actas do Encontro sobre Arqueologia da Arrábida. Lisboa: Instituto Português de Arqueologia 14: 21-43

ARnAUD, J.M. 1986. ARNAUD, J. M. 1986. Post -glacial adaptations in southern Portugal: a summary of the evidence. In The Pleistocene Perspective: Innovation, Adaptation and Human Survival. World Archaeological Congress. London: Allen \& Unwin: 1-15.

BRONK RAMSEY, C. 2009. Bayesian analysis of radiocarbon dates. Radiocarbon, 51 (1): 337-360

Cunha, E. \& Umbelino, C. 2001. Mesolithic people from Portugal: an approach to Sado osteological series. Anthropologie, 39, 2-3: 125-132.

DINIZ, M. \& ARIAS, P. 2012. O povoamento humano do paleoestuário do Sado (Portugal): problemáticas em torno da ocupação dos concheiros mesolíticos. In: A. Campar Almeida, A. Bettencourt, D. Moura, S. MonteiroRodrigues \& M. I. Alves (eds.), Environmental changes and human interaction along the Werstern Atlantic Edge (Mudanças ambientais e interacção humana na Fachada Atlântica Ocidental), Coimbra, APEQ, CITCEM, CEGOT, CGUP, CCT: 139-157.

DINIZ, M. 2007. O sítio da Valada do Mato (Évora): aspectos da neolitização no Interior/Sul de Portugal. Lisboa: Instituto Português de Arqueologia. (Trabalhos de Arqueologia, 48).

GABRIEL, S. 2010. Mesolithic fishing in Portugal: newarchaeo-ichthyological data. Comunicação apresentada ao Eighth International Conference on the Mesolithic in Europe. Santander, 13-17.

Gabriel, S; Prista, N. \& CostA, M. J. 2012. Estimating meagre (Argyrosomus regius) size from otoliths and vertebrae. Journal of Archaeological Science, 39: 2859-2865.

García Díaz, V. \& Clemente Conte, i. 2011. Procesando pescado: reproducción de las huellas de uso en cuchillos de sílex experimentales. In: A. Morgado Rodríguez, Baena Presley, D. García (eds.), La Investigación Experimental aplicada en la Arqueología, Granada, Departamento de Prehistoria y Arqueología - Universidad de Granada: 163-169.

GibaJA, J.; JosÉ IBÁÑEZ, J.; RodrÍGUEZ, A.; EMILIO GonzÁlez, J.; Clemente, I.; García, V. \& PerALES U. 2010. Estado de la cuestión sobre los estudios traceológicos realizados en contextos mesolíticos y neolíticos del sur peninsular y noroeste de África. In: J. Gibaja \& A. Carvalho (eds.), Os últimos caçadores-recolectores e as primeiras comunidades produtoras do sul da Península Ibérica e do Norte de Marrocos, Faro, Universidade do Algarve (Promontoria Monográfica; 15): 181-190. 
HaRdy B. L.; Moncel M.-H. 2011. Neanderthal Use of Fish, Mammals, Birds, Starchy Plants and Wood 125-250,000 Years Ago. PLoS ONE, 6:8: e23768.

INIZIAN, M.-L.; RÉDURON-BALLINGER, M.; ROCHE, H. \& TIXIER, J. 1999. Technology and Terminology of Knapped Stone. Traduzido por Jehanne FéblotAugustins, Nanterre, CREP (Préhistoire de la Pierre Taillée, 5), $189 \mathrm{p}$

MARChAND, G. 2001. Les traditions techniques du Mésolithique final dans le Sud du Portugal: les industries lithiques des amas coquilliers de Várzea da Mó et Cabeço do Rebolador (fouilles M. Heleno). Revista Portuguesa de Arqueologia, 4:2: 47-110.

Martins, J. M.; A. F. Carvalho; A. M. Soares. 2008. A calibração das datas de radiocarbono dos esqueletos humanos de Muge. Promontoria Monográfica 6 : 73-93.

NuKushinA, D. 2012. Tecno-tipologia lítica e cronometria no Mesolítico final do vale do Sado: $O$ caso do concheiro das Amoreiras (Alcácer do Sal). Tese de mestrado, Faculdade de Letras da Universidade de Lisboa, disponível em WWW: URL: http:// hdl.handle.net/10451/7933.

Pimentel, N.; Diniz, M.; ArIAs, P.; NuKushinA, D. 2013. Lithic materials in the Sado River's shell middens geological provenance and impact on site location. Poster apresentado em Muge 150th, conference on the 150th anniversary.

Reimer, P.; E. BArd, A. BAyliss, J. W. BeCK, P. G. Blackwell, C. Bronk Ramsey, P.M. Grootes, T. P. Guilderson, H. Haflidason, I. Hajdas, C. Hattž, T. J. Heaton, D. L. HoffmanN, A. G. HogG, K. A. Hughen, K. F. Kaiser, B. Kromer, S. W. Manning, M. NiU, R. W. Reimer, D. A. Richards, E. M. Scott, J. R. Southon, R. A Staff, C. S. M. Turney, J. VAN Der Plicht. 2013. IntCal13 and Marine13 Radiocarbon Age Calibration Curves 0-50,000 Years cal BP. Radiocarbon. 55(4): 1869-1887.

Richards, M.P., Hedges, R.E.M. 1999. Stable isotope evidence for similarities in the types of marine foods used by Late Mesolithic humans at sites along the Atlantic coast of Europe. Journal of Archaeological Science. 26: 717-722.

TIXIER, J.; InIZIAn, M.-L ; Roche, H. 1980. Préhistoire de la pierre taillée. 1: terminologie et technologie. Paris, Centre National de la Recherche Scientifique.

ZILHÃo, J. 1997. O Paleolítico Superior da Estremadura Portuguesa. Lisboa, Colibri, 2 vol. 